\section{PRECARIEDAD URBANA, DESALOJOS Y VIVIENDA EN EL CENTRO HISTÓRICO DE LIMA'}

Manuel Dammert Guardia²

\section{Resumen}

Este artículo discute los mecanismos de acceso residencial en inmuebles deteriorados en el área central histórica de Lima, las disputas por el uso de suelo y el desalojo como forma de apropiación de los predios. Con información cualitativa proveniente de trabajo de campo en el centro de Lima, la propuesta que subyace es que Barrios Altos se ha ido transformando en un área urbana precarizada desde mediados del siglo XX, lo cual se expresa principalmente en los asuntos de la propiedad, las estrategias residenciales y de tenencia. En este ámbito, los desalojos configuran las estrategias y repertorios de acción de los residentes que viven

\section{URBAN PRECARITY, EVICTIONS AND HOUSING IN THE HISTORIC CENTER OF LIMA'}

\author{
Manuel Dammert Guardia²
}

\section{Abstract}

This paper addresses the mechanisms for residential access to deteriorated buildings in the historic central area of Lima, disputes over land use and evictions as a way of appropriating property. Based on qualitative information from field work in the center of Lima, it is suggested that Barrios Altos has been turning into a precarious urban area since the mid-twentieth century. This precarity is expressed mainly in property issues, residential strategies, and tenure. In this context evictions configure the strategies and actions of residents who live in the middle of the principal tensions in the area: the dispute between residential function and the need 
en medio de la tensión principal del área: la disputa entre las funciones residenciales y la necesidad de expansión de las centralidades metropolitanas de comercio y servicios. Este tema tiene la peculiaridad de ser poco atendido por la investigación urbana, por lo que la intención es aportar una crítica en el estudio de las áreas históricas centrales y contribuir en la comprensión de la reproducción residencial de los sectores populares.

\section{PALABRAS CLAVE:CENTROHISTÓRICO;DESALOJOS; PRECARIEDAD URBANA; VIVIENDA; LIMA.}

Recibido: 18-10-2017

Aceptado: 09-10-2018

1 Este trabajo fue financiado por la Dirección de Gestión de la Investigación de la PUCP, a través de la subvención 70242.2165. Además, el proyecto colectivo (subvención 70243.0106) permitió al autor realizar una nueva ronda de trabajo de campo. Agradezco los comentarios de los dos evaluadores anónimos que permitieron elaborar una nueva versión del artículo. La responsabilidad del escrito es del autor.

2 Perú. Pontificia Universidad Católica del Perú. ORCID: http://orcid.org/0000-0001-7583-1878. Correo electrónico: manueldammert@gmail.com. for an expansion of urban centralities for trade and services. This topic has the peculiarity of being disregarded by urban research; therefore, the aim is providing a critical point of view in the study of central historical areas and contributing to a better understanding of residential reproduction in working class sectors.

\section{KEYWORDS: HISTORIC CENTER; EVICTIONS; URBAN} PRECARITY; HOUSING; LIMA

Received: 18-10-2017

Accepted: 09-10-2018

1 This paper was funded by the Research Management Department, PUCP, through grant No 70242.2165. The development of collective research (grant No 70243.0106) enabled the author of this study to conduct new field work. Appreciation is extended to all peer reviewers whose comments enabled the development of a new version of this paper. The author retains full responsibility for the text.

2 Peru. Pontifical Catholic University of Peru. ORCID: http://orcid. org/0000-0001-7583-1878. Email: manueldammert@gmail.com. 


\section{Introducción}

Las áreas centrales históricas se caracterizan por una serie de paradojas y tensiones: alta concentración de patrimonio material; alta densidad de residentes en situaciones de pobreza y precariedad tanto laboral como residencial; y fragmentación socio-espacial como modelo de producción urbano. Los centros históricos son "espacios disputados" (Duhau y Giglia, 2004) por la multiplicidad de funciones urbanas que realizan (Carrión, 2010; Delgadillo, 2008a y 2008b; Hiernaux y González, 2008; Rojas, Rodríguez y Wegelin, 2004) y los conflictos que se derivan de ellas. La tensión más importante se deriva de la coexistencia de funciones residenciales y funciones de centralidad urbana (empleo y movilidad) (Coulomb, 2012; Dammert Guardia, 2017).

En las últimas décadas, la investigación urbana ha privilegiado el análisis de los procesos de recambio poblacional, desplazamiento y gentrificación, los impactos territoriales del turismo, el carácter de espacio público de las centralidades históricas, o las políticas de preservación del patrimonio material.
Este artículo aborda una temática que pasa desapercibida en los debates actuales: los desalojos y las disputas por el uso del suelo en áreas centrales tugurizadas. El tema se desarrollará en torno a tres argumentos centrales: primero, las áreas centrales históricas se consolidan como modelos de fragmentación socio-espacial. Junto con la existencia de áreas "privilegiadas" (de intervenciones públicas y privadas, asociadas al turismo y la recuperación urbana), existen otras áreas caracterizadas por la disputa del uso de inmuebles deteriorados para reconvertirlos en usos comerciales y depósitos (formales e informales). En segundo lugar, se demuestra que los residentes son sujetos activos que despliegan estrategias y repertorios de acción frente a los conflictos por el suelo y la propiedad, y la inseguridad de la tenencia. La posibilidad de ser desalojados forma parte de la cotidianidad y, pese a que son eventos disruptivos, son normalizados y organizan el tiempo social y las estrategias residenciales. En tercer lugar, los procesos descritos configuran un proceso de precarización urbana, de acumulación de desventajas sociales. De esta manera, este texto establece un aporte crítico en el estudio de las áreas históricas centrales y en la comprensión de la reproducción residencial de los sectores populares. 
La discusión se centra en el estudio de caso de Barrios Altos ${ }^{3}$, una de las áreas residenciales que conforman el distrito de Cercado de Lima y el Centro Histórico de Lima (CHL, en adelante). Este barrio se caracteriza por los conflictos por el uso residencial de los inmuebles debido a la presión que ejerce la centralidad comercial y su requerimiento de espacios próximos para la instalación de almacenes y, en menor medida, la especulación urbana dado el incremento del valor del suelo. La disputa por el uso del suelo involucra -a grandes rasgos- a dos actores: por un lado, los vinculados a las actividades comerciales en torno a Mesa Redonda y el Mercado Central (también ubicados en el Cercado de Lima), que constituyen la segunda centralidad metropolitana de puestos de trabajo más importante (González y Pozo, 2012); y, por otro, los residentes de predios tugurizados de Barrios Altos.

El tugurio es un mecanismo de acceso residencial de los sectores "populares" en áreas centrales de la ciudad y que se definen como predios que poseen las siguientes características: hacinamiento, materiales inadecuados, limitaciones en el acceso a servicios básicos, vulnerabilidad de la propiedad. En Barrios Altos existen distintas tipologías de viviendas colectivas: quintas, conventillos, casa vecindad, callejones, etc. Se diferencian por fecha de construcción, tipo de construcción, modificaciones. En este artículo se usa indistintamente la denominación de "vivienda colectiva" o quintas para referirnos a los distintos tipos de inmuebles (véanse Dreifuss, 2005; Henry, 1977; Panfichi, 1995).

En el distrito de Cercado de Lima se encuentra uno de cada cuatro predios tugurizados de toda la ciudad y más de 10 mil familias en Barrios Altos residen en estos inmuebles. La bibliografía sobre tugurios en Lima ha señalado la vulnerabilidad de la propiedad, las formas de organización de vida cotidiana y los vínculos que establecen los residentes, los mecanismos de reproducción de pobreza, la ausencia de políticas de renovación urbana y la configuración de un espacio "residual" de las políticas patrimoniales (Arroyo, 1994; Chirinos, 1996; Henry, 1977; Harms, 1997; Ludeña, 2011; Panfichi, 2013; Sánchez León, Guerrero y Calderón, 1979).

Este artículo discute cómo -en un contexto de reconfiguración del área central histórica de la ciudad a partir de la década de los noventas (Ludeña, 2002, 2011)- los procesos de desalojo configuran los repertorios de acción de los residentes y actores interesados en el uso de los predios.

Los desalojos son un problema invisible de la vivienda (Hartman y Robinson, 2003) y es difícil saber con exactitud su magnitud (Desmond y Shollenberger, 2015). Tienen repercusiones negativas en términos psicológicos, de salud o de la

3 Son dinámicas urbanas transversales a otras áreas residenciales del centro histórico. 
FIGURA 1. LÍMITE DEL CENTRO HISTÓRICO DE LIMA (AL MAPA ORIGINAL SE LE HA AGREGADO -DE MANERA REFERENCIAL- LA UBICACIÓN DE BARRIOS ALTOS).

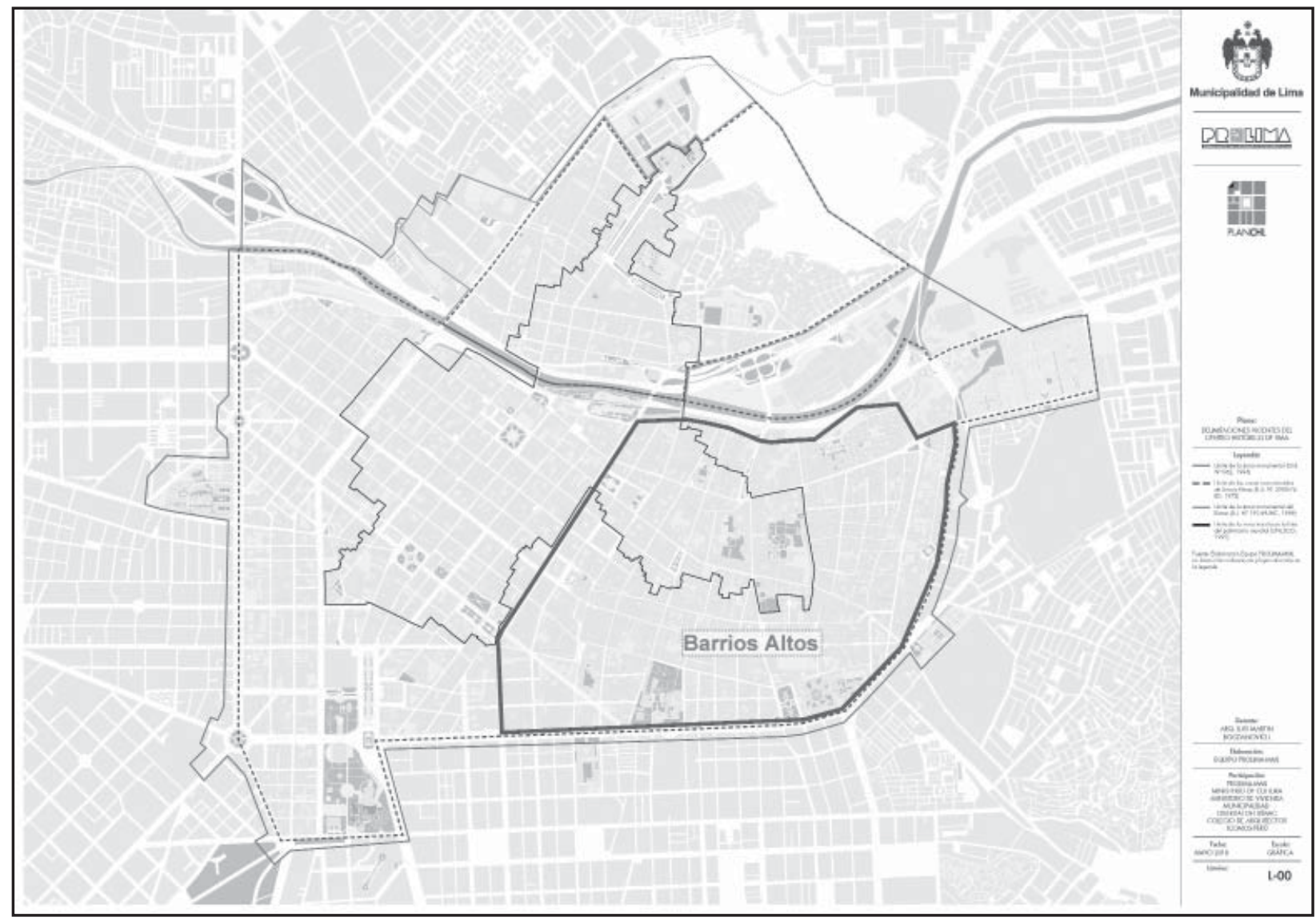

Fuente: PROLIMA (2018) 
posibilidad de acceder a un mejor entorno residencial (Desmond y Bell, 2015). Además, los desalojos configuran una dimensión central de la precariedad urbana, puesto que reproducen la condición de pobreza de sus habitantes (Desmond, 2012, 2016) y están asociados a las dinámica de desplazamiento que son el centro del "modelo de acumulación por desposesión del hábitat" (Janoschka, 2016, p. 38). Por estas razones, representa un tema fundamental para la comprensión de las transformaciones urbanas (Brickell, Fernández, y Vasudevan, 2017; Desmond, 2016; Delgadillo, 2016a y 2016b; Janoschka, Sequera y Salinas, 2014; Muñoz, 2017; Slater, 2006; Toscani, 2018; Purser, 2016).

Se debe advertir que Barrios Altos representa un caso de continuidad en el tiempo de precarización urbana. Los desalojos no son una situación nueva en el CHL y en áreas como Barrios Altos. Lucía ${ }^{4}$ había vivido toda su vida en una de estas "quintas" del CHL hasta que el desalojo de ella y su padre fue inevitable. Desde finales de la década de 1990 empezaron las presiones por desalojar a su familia y vecinos para de construir un centro comercial (o depósito) en el terreno.

"Hicieron un huaqueo [saqueo] y se metieron por todos los cuartos. Empezaron a tumbar encima de uno las casas. Eran 40 familias, y las 40 familias

4 Todos los nombres se han modificado para mantener el anonimato. todas se han ido asustadas. Se fueron de miedo, pues, ¿no? Porque los matones venían a demoler".

El desalojo fue ilegal, pero bastó con que iniciara el juicio para forzar la salida de los residentes. Lucia se mudó a un cuarto de otra quinta a unas cuantas cuadras, pagando al inquilino anterior para su traspaso. Luego de costear el alquiler durante unos meses, ha dejado de pagarlo, al igual que sus vecinas, y se enfrenta a un nuevo proceso de desalojo.

El artículo se organiza de la siguiente manera: la primera sección expone la metodología del estudio. A continuación, la descripción el estudio de caso. La tercera sección discute el tipo de arreglos de propiedad existentes en Barrios Altos. La cuarta sección hace referencia a los desalojos y su relevancia para comprender las estrategias que adoptan los residentes. Finalmente, los argumentos desarrollados llevan al planteamiento de algunas líneas conclusivas a manera de cierre.

\section{Metodología}

El trabajo de campo ${ }^{5}$ se realizó entre los años 2010 y 2014. Se realizaron alrededor de 100 entrevistas semiestructuradas a residentes y miembros de

$5 \quad$ El trabajo de campo contó con el valioso apoyo de Tania Ramírez e Ivonne Méndez. 
juntas vecinales del distrito de Cercado de Lima (respetando cuotas de edad y sexo) de Barrios Altos y otras áreas del distrito (74 entrevistas), a funcionarios públicos (10 entrevistas), comerciantes y trabajadores de Mercado Central y Mesa Redonda (cinco entrevistas), y especialistas en el tema (ocho entrevistas). Adicionalmente, se aplicaron instrumentos de observación en las áreas públicas y viviendas colectivas con el objetivo de problematizar patrones de convivencia, usos y formas de apropiación del espacio público, así como para complementar las entrevistas realizadas.

El acceso al trabajo de campo se organizó en torno a las asociaciones vecinales, contactándolas directamente gracias al registro de asociaciones que posee la Municipalidad Metropolitana de Lima, o a través de instituciones de la sociedad civil que poseen una importante trayectoria de trabajo en esta zona, como es el caso de CIDAP (Centro de Investigación, Documentación y Asesoría Poblacional). Una vez establecidos los contactos iniciales, se realizó una estrategia de "bola de nieve" que permitiera ampliar el número de entrevistas. La información cualitativa permite identificar las estrategias que despliegan los residentes. El propósito es visibilizar estos hechos no como acciones individuales. Por el contrario, interesa utilizar la información de las entrevistas para construir casos típicos bajo el supuesto de que sus estrategias forman parte de repertorios compartidos, marcos de referencia comunes. La discusión en este artículo fue tomada de los casos de residentes que poseen mayor inseguridad de la tenencia y residen en predios tugurizados.

Es importante señalar algunos rasgos de la coyuntura en la que se realizó el trabajo de campo. Por un lado, el gobierno municipal estaba a cargo de un grupo político de izquierda liderado por Susana Villarán (2010-2014), que elaboró una serie de normativas, operativos y un discurso público acerca de la necesidad de enfrentar los desalojos y la situación de pobreza de los residentes del distrito de Cercado de Lima. Expresión de esto son los intentos por elaborar la actualización del Plan Maestro del Centro Histórico, el Protocolo de Intervención en Caso de Desposesión Legal (un instrumento de carácter no normativo, que tenía por objetivo brindar información a los residentes que enfrentaran procesos de desalojo), operativos realizados por la fiscalía municipal para cerrar depósitos ilegales, entre otras acciones. Pese a esto, no se lograron resultados trascendentes en materia de renovación urbana y vivienda en áreas centrales históricas. Por otro lado, el gobierno nacional promulgó la Ley 29415 sobre saneamiento físico legal de predios tugurizados con fines de renovación urbana (y su posterior reglamento el año 2010) que generó incentivos para la creación de asociaciones vecinales y cambios en la estructura institucional de la municipalidad (la creación de una subgerencia de renovación urbana). Estos dos aspectos promovieron una "ventana de oportunidad" para la 
asociación vecinal (requisito establecido por la Ley 29415) y la visibilidad de los problemas de desalojo y necesidad de discutir un proyecto renovación urbana en el distrito de Cercado de Lima.

\section{Configuración de la precariedad urbana}

El CHL es resultado de la urbanización de ciudad (Hardoy y Gutman, 1995). Desde fines del siglo XIX, se inició la movilidad residencial de sectores medios y altos desde el área céntrica hacia nuevas áreas de expansión urbana (Ludeña, 2002), situación que se consolidó en las primeras décadas del siglo XX. En paralelo, el crecimiento poblacional, debido a la migración interna -desde la década del cuarenta, principalmente-, se manifestó en las distintas estrategias de acceso residencial de los sectores populares: por un lado, las invasiones y producción de vivienda en áreas periféricas o suelo de mala calidad en espacios centrales; y, por otro, el acceso residencial en áreas urbanas centrales a través del alquiler y la vivienda colectiva.

A diferencia de los "asentamientos informales" (Calderón, 2005; Driant, 1991), los tugurios o viviendas precarias en áreas centrales corresponden al deterioro del conjunto de estos espacios urbanos. Estas particularidades se pueden comprender mejor si presentamos un resumen de los principales momentos de transformación del CHL y de la trayectoria de los inmuebles destinados a vivienda ubicados en áreas como Barrios Altos. En el primer momento, en Barrios Altos coincidían inmuebles de propiedades de distintos sectores sociales, instituciones públicas, universidades y viviendas de sectores trabajadores. Hasta finales del siglo XIX, "coexistían en espacios residencialmente cercanos la heterogénea plebe limeña y familias provenientes de la aristocracia" (Panfichi, 1995, p. 34). El segundo momento inició durante la primera mitad del siglo XX, en que la expansión de la ciudad y la urbanización de áreas destinadas a sectores medios y altos dio paso a una "estrategia rentista de las familias e instituciones propietarias de estos predios [a través de la venta, construcción de viviendas colectivas y alquiler director de sus propiedades] [ubicados en el área central]" (Panfichi, 2013). Es decir, es el establecimiento del régimen de inquilinato y la consolidación de un perfil de residente más homogéneo de sectores populares.

En el tercer momento, que se consolida durante la segunda mitad del siglo XX, se agudiza el deterioro material del centro histórico en su conjunto, debido a la ausencia de políticas públicas. Durante este periodo se termina de consolidar el tugurio como modelo residencial, la pérdida de valor de los inmuebles en áreas centrales y la precarización de la propiedad (Programa de Naciones Unidas para el 
Desarrollo [PNUD], 2005). Entre 1981 y 2004, las viviendas tugurizadas en el distrito de Cercado de Lima pasaron de 15,660 a 27,094 (CIDAP). Entre los factores estructurales asociados a esta situación, se encuentra: las políticas de control de precios de alquiler en áreas centrales, la ausencia de políticas de vivienda para sectores de bajos recursos, las dinámicas de inserción migratoria y rol de recepción que cumplían las viviendas en áreas centrales. Además, incrementan los problemas en la regularización de la propiedad debido a problemas judiciales, fallecimiento de antiguos propietarios, y acciones de compraventa legales, irregulares o ilegales.

Los arreglos de la propiedad son múltiples y complejos. Un residente narra así el caso de la quinta en la que vive:

"los propietarios [originales] eran 7 hermanos, y uno de ellos era de los que arrendaban a los subarrendatarios y ya, pues. De ahí no se supo más nada hasta que un día vino la señora que decía que era la dueña. Pero nosotros no conocíamos, nunca conocimos quien era dueño. Siempre sabíamos que había herederos, pero nunca conocimos quienes eran dueños".

El caso de otra quinta permite entender aún más los problemas vinculados a la propiedad: "El predio perteneció a una persona natural, fue siempre un lugar de vivienda, pero con el paso de los años la señora se quedó sola, y se quedó con la totalidad del predio". Al fallecer, le dejó el predio a una asociación religiosa.
"Luego, en el año 71, las madres [monjas] le venden a un tal señor que es el que compra el predio y que les ha venido cobrando la renta del momento en que ingresó. Nosotros lo consideramos como propietario y le pagamos a él la renta, pero con el tiempo nos dimos cuenta de que él no era propietario, que no tenía inscrita la propiedad en Registros Públicos».

Durante este periodo, la situación inicial de inquilinato de sectores bajos ha dado paso a la existencia de "precaristas" (ex-inquilinos que dejaron de pagar alquiler, y, además, subarrienda)" (Calderón, 2005, p. 51). Los arreglos de propiedad son irregulares y los inmuebles presentan problemas de propiedad, juicios y tráfico ilegal de propiedad. Estas características marcan una diferencia respecto a los regímenes de inquilinato en los "asentamientos irregulares" (Rodríguez, Rodríguez y Zapata, 2018). En los asentamientos -caracterizados por dinámicas de "urbanización inversa" (Pírez, 2016)-, el inquilinato puede corresponder a una estrategia de acumulación de capital "informal". Sin embargo, en las áreas centrales se da la pérdida de valor de los inmuebles, junto con la consolidación de un modelo de precarización de la vivienda y del régimen de inquilinato.

El marco normativo del inquilinato en las áreas centrales y en los tugurios ha tenido pocos cambios en las últimas décadas. Las leyes de inquilinato se han concentrado en controlar y otorgar mayor seguridad al inquilino en gran parte del siglo XX, con excepción de hitos como el de 1977 cuando 
el Estado fijó las rentas para los alquileres de estos predios (Decreto Ley 21938). Aunque se modificó durante el gobierno de A. Fujimori (1991) con la derogación y modificación a la ley (Decreto Ley 709-Ley de promoción a la inversión privada en predios para arrendamientos), que contempla una protección temporal (por tres años) para los residentes de predios que tengan un valor bajo de autoevalúo. Esta protección se ha ampliado luego en distintas ocasiones.

En el cuarto momento - a partir de la década de los noventa- se suma un rasgo adicional: los inmuebles adquieren mayor valor para usos asociados a las actividades de comercio y servicios presentes en el entorno (Mercado Central, Mesa Redonda). Es decir, se revaloriza el uso del suelo no residencial debido a la saturación del área comercial y la necesidad de ocupar predios del entorno para fines de localización de productos (depósitos) o galerías de venta.

La década de los noventa representará un nuevo contexto para el CHL (Ludeña, 2002), pues la gestión del alcalde Andrade (1996-2001) realizará una importante intervención para recuperar el centro histórico con la formulación del Plan Estratégico de Recuperación del Centro Histórico (1998). Dos aspectos caracterizaron estas intervenciones: la "remodelación y puesta en valor de los espacios públicos de mayor densidad simbólica" (Chion y Ludeña 2005, p. 154); y la reubicación de comerciantes informales que ocupaban las calles del centro. Así, en los años noventa el centro cambiará de rostro, aunque solo de manera parcial. Durante la década de 2000, el centro adquirió nuevas características en términos de las intervenciones público y privadas, seguridad en el núcleo histórico del CHL, entre otros. A esta situación, se agrega que durante la gestión del alcalde Castañeda (2002-2010), caracterizada por la ausencia de un proyecto para el centro, se aprobó la desregulación de los usos del suelo (Ordenanza 0893, 2005) flexibilizando las restricciones y el desarrollo de mayor número de actividades económicas en el centro.

El centro histórico de Lima tiene una extensión de 1,022.81 ha, distribuida en los siguientes distritos: 68\% en el Cercado de Lima, 28\% en el distrito del Rímac y 04\% en otros distritos del entorno (Figura 1). El área declarada patrimonio cultural de la humanidad en 1991 por la UNESCO es de 239.69 Ha. (23\% del total del CHL), y según el Censo 2007 , tiene 146,126 habitantes, de los cuales 67\% corresponde al Cercado de Lima, 32\% al distrito del Rímac y el 0,1\% restante a otros distritos

Del número total de predios del centro histórico, 83,636 son de vivienda donde habitan aproximadamente 125,265 residentes, "[...] de los cuales 99,557 (80\%) viven en la parte correspondiente al Cercado de Lima y las restantes 25.708 personas (20\%) viven en el Rímac" (INDECI, 2012). De acuerdo con los cálculos del CIDAP, el distrito del Cercado de Lima concentra el mayor número de 
viviendas tugurizadas en toda el área metropolitana de Lima (15,660 en 1993, 18,087 en 1999 y un estimado de 27,094 en 2004). Para 2007, el cálculo es de 110,985 predios tugurizados, de los cuales 24.41\% está ubicado en el distrito de Cercado.

Otro rasgo central del CHL es su pérdida de población residencial. Según la información de los censos, en 1972 en el Cercado de Lima residían 366,763 personas y la cifra aumentó en 1981 (390,447); luego empezó a reducir significativamente en las siguientes mediciones censales: 345,233 residentes en 1993; 299,493 en 2007, y 268352 en 2017. Es decir, entre 1981 y 2017 la población residente se redujo en más de 30\%.

A solo unas cuadras del "damero de Pizarro" se encuentra Barrios Altos. Este emblemático lugar de Lima se encuentra estigmatizado como un área peligrosa de la ciudad. Barrios Altos es un área de acumulación de desventajas sociales y precariedad urbana, donde residen aproximadamente 75 mil personas en casi 300 manzanas. Además, este barrio concentra la mitad de los tugurios del distrito del Cercado. El área presenta problemas de infraestructura de los servicios básicos (agua, desagüe, electricidad) y las viviendas poseen condiciones materiales no adecuadas y hasta llegan a ser catalogadas como inhabitables.

\section{Tugurio, propiedad y acceso residencial}

Los tugurios en Barrios Altos son un tipo de acceso residencial para sectores de bajos recursos (Carrión, 1992). De acuerdo con Abramo (2012) existen distintas lógicas de producción del espacio urbano, diferenciadas si predomina una lógica del mercado formal, la del Estado o la lógica de la necesidad. Desde la segunda mitad del siglo XX, Barrios Altos se sitúa en la lógica de la necesidad, en la medida que gran parte de las transacciones actuales de acceso a la vivienda (invasión, posesión, alquiler u otras) poseen los siguiente rasgos: no están totalmente reguladas o normadas, operan en los márgenes de lo "informal e ilegal", no corresponden a la idea de la maximización de las ganancias, uno de sus principales recursos son las redes sociales (de conocidos, por ejemplo), ya que no existen actores inmobiliarios y son una forma de resolver el problema habitacional para una población en una posición estructural desventajosa. Sin embargo, poseen otra serie de particularidades que resultan de los arreglos de propiedad y las formas de acceso residencial que predominan en esta área.

En Barrios Altos, más de $50 \%$ de los arreglos de tenencia son de alquiler, $38 \%$ es propia y $10 \%$ está 
FIGURA 2. INMUEBLES CON DECLARACIÓN DE INHABITABILIDAD 1967-2016.

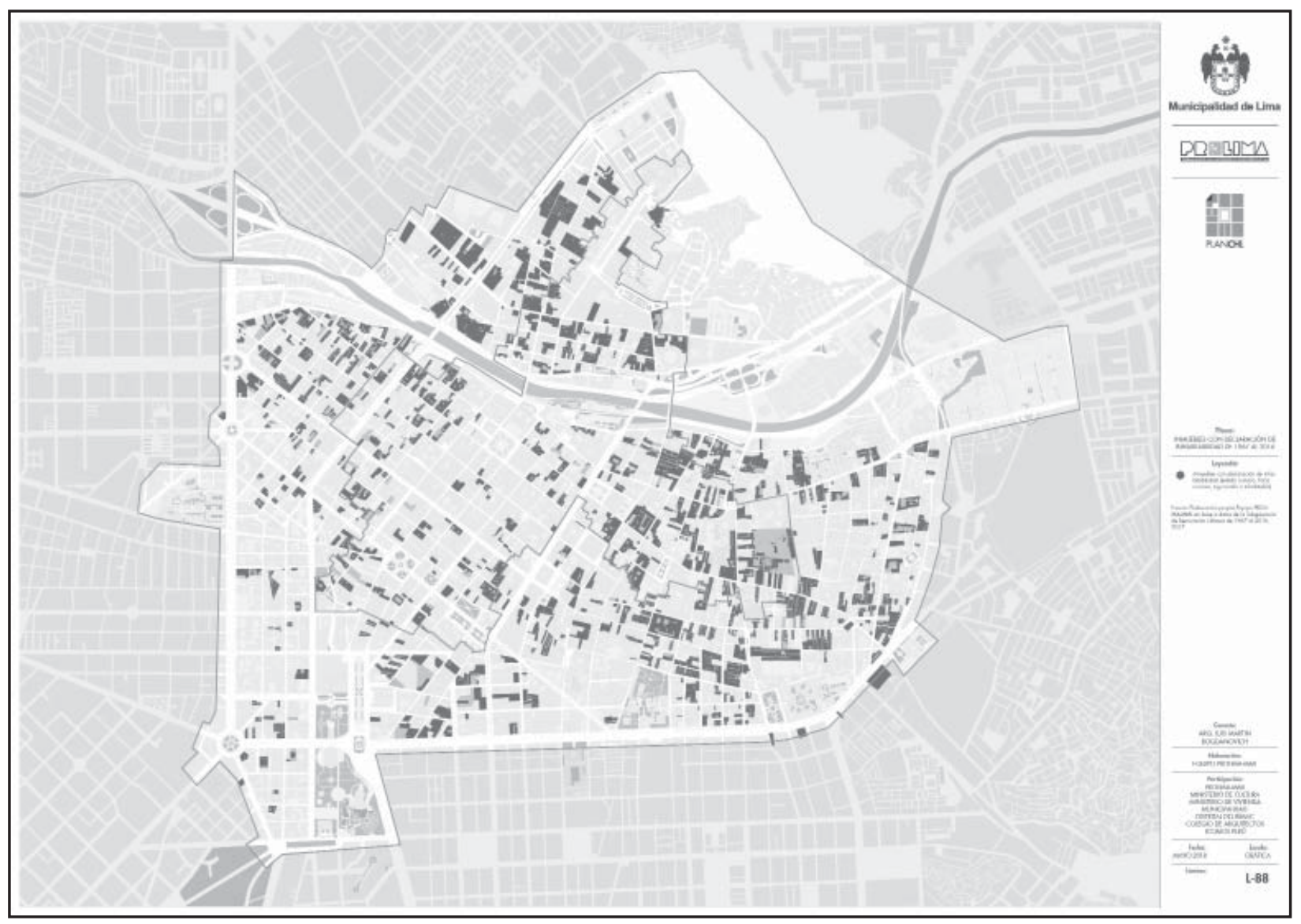

Fuente: PROLIMA (2018). 
FIGURA 3. USOS ACTUALES DEL SUELO.

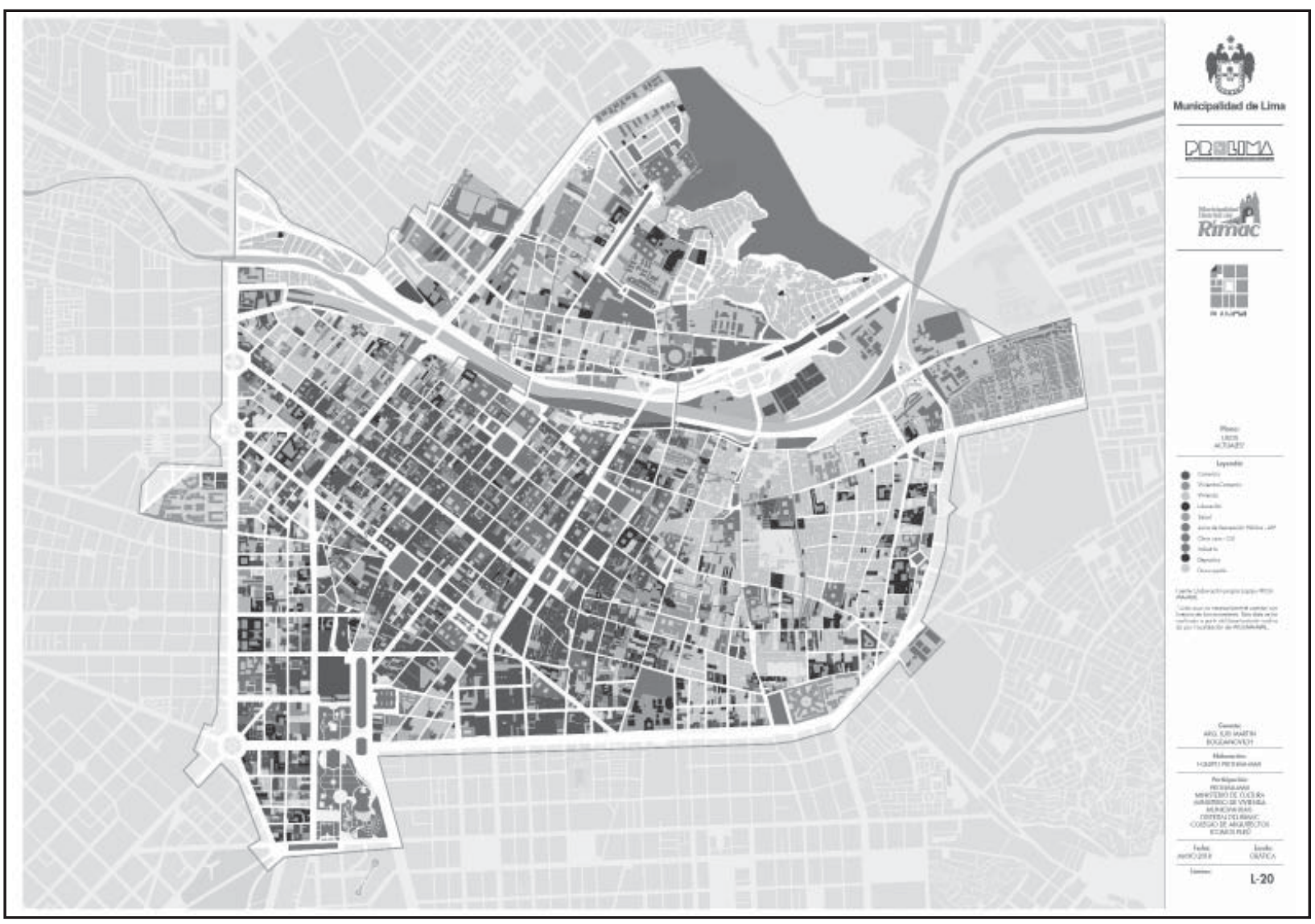

Fuente: PROLIMA (2018) 
en posesión ${ }^{6}$. Además, tres de cada cuatro predios están destinados a la vivienda, lo cual expresa su carácter residencial. Sin embargo, las cifras no retratan la situación real de los usos en Barrios Altos. Del total de predios de uso residencial, se calcula que entre $30 \%$ y $50 \%$ tienen uso mixto o son modificados para servir como depósitos y almacenes formales o "clandestinos" para los comerciantes que operan en el entorno.

En este punto es necesario hacer algunas precisiones para el lector. Los inmuebles son de vivienda colectiva, en la medida que existen espacios internos independientes pero que comparten espacios comunes. Existen diferencias importantes en el tamaño de las quintas: pueden tener entre 20 a más de 100 espacios independientes en su interior. A esta situación, se debe agregar otra precisión. La propiedad -originalmente-comprendía todo el predio (es decir, el inmueble en su conjunto y todos los espacios que se alquilaban en su interior). Con el paso del tiempo, se encuentran casos donde aún existe propiedad de todo el inmueble o casos donde se ha dividido la propiedad, con lo cual cada espacio residente en el interior posee un

6 Para 1940, el alquiler alcanzaba el 90.9\% de las viviendas (Panfichi, 2013). título. Además, existen diferencias sobre quien es el propietario. Pueden existir propietarios privados o públicos. En el caso de la propiedad privada, también se incluye a la Beneficencia de Lima.

Retomemos la exposición. Como resultado de los momentos descritos, se propone que los arreglos de propiedad de las viviendas colectivas o multifamiliares del centro histórico y Barrios Altos se diferencian por las características de la propiedad y tenencia del predio ${ }^{7}$.

\section{Existen tres figuras básicas.}

1. El propietario regularizado que cuenta con título de propiedad, tanto a nivel de las viviendas en las que se dividen las quintas o de las quintas en su conjunto (con inquilinos en su interior). Los propietarios de vivienda al interior son el resultado de acciones de compra y venta, y/o de regularización de la tenencia. Los propietarios de los inmuebles en conjunto enfrentan distintos problemas: los inmuebles requieren una carga adicional de trámites, especialmente los inmuebles con valor monumental; tienen problemas con los residentes, ya sea

7 De acuerdo con el estudio del PNUD (2005), existen 10 tipologías que combinan el tipo de propiedad (poseedor, inquilino, propietario), tipo de propietario (público, privado, religioso o abandonado), si son inmuebles catalogados como patrimonio, si tienen construcciones informales, y si tienen poseedores de mala fe. El estudio se refiere al caso de Rímac, pero es posible plantear que es aplicable también para el distrito de Cercado de Lima. 
porque se encuentran en situación de alquiler o porque son poseedores precarios; encuentran que la regularización de la propiedad está desactualizada debido a la existencia de múltiples herederos o por procesos de compra y venta no registrados.

2. Las personas que tienen derechos de posesión, esto es, residentes de un predio por un periodo de tiempo sin la presencia mediadora de una persona reconocida como propietario y que intervenga en el predio.

3. Los habitantes en posesión precaria, quienes hoy se encuentran en posesión de un bien sin título posesorio o que han tenido un título que ya ha fenecido por expiración, anulación u otro. También se consideran poseedores precarios quienes han tenido algún contrato de alquiler, pero que se encuentra vencido.

Para comprender el régimen de tenencia en Barrios Altos (vulnerabilidad y precariedad) es necesario considerar los incentivos o razones para residir en esta área. La principal razón es la ventaja que su localización agrega a la posibilidad de acceso a puestos de trabajo. La centralidad -del área histórica y de las áreas comerciales de Mesa Redonda y Mercado central- otorga beneficios a las personas que residen en Barrios Altos. Los residentes que se dedican a actividades de comercio informal se benefician directamente de masiva confluencia de personas en el CHL. Hay otros que se dedican a realizar trabajos para las comercializadoras ubicadas en el centro, como puede ser el trabajo en zapatería o confecciones. Las personas que se dedican a actividades comerciales y de servicio -de manera informal y sin estabilidad laboral- dependen directamente de la información que circula entre las redes sociales localizadas en estas áreas. Los problemas habitacionales están vinculados directamente al empleo informal que realizan gran parte de sus residentes y que solo puede ser sostenida por la proximidad a los puestos de trabajo, espacios de comercialización y de venta de la fuerza de trabajo (así sea en condiciones informales, precarias y con alto nivel de inestabilidad).

\section{Desalojos, estrategias y espera}

El desalojo es resultado del conflicto entre residentes y propietarios (o supuestos propietarios) y de mecanismos irregulares de toma de posesión del predio. Y no es una característica nueva en $\mathrm{Ba}$ rrios Altos (Chirinos, 1996; Custers, 2001; Harms, 1997). El continuo deterioro de los inmuebles y precarización de la propiedad durante gran parte del siglo XX tuvo como correlato la precarización de la propiedad y la inseguridad de la tenencia. Sin 
embargo, en las últimas dos décadas se ha modificado la visibilidad y alcance de estos conflictos. No existen cifras o estudios que permitan comprender la magnitud de los desalojos debido al carácter de éstos y a un número importante en donde la ejecución no se da por la vía judicial.

Para comprender el caso de Barrios Altos es necesario revisar las estrategias y repertorios de acción que adoptan los residentes y los propietarios. Rao (2013) propone que la "legalidad en los márgenes es una categoría inestable que no está resuelta solo por las estrategias de supervivencia de las personas en crisis, pero también por los incontables desfases en procesos burocráticos" (p. 760). En tal sentido, las estrategias de los actores también reorganizan la relación con el Estado y las leyes, y modifican los límites entre lo legal y lo ilegal. Esta situación incrementa la desventaja estructural de sus residentes. A continuación, se destacan cinco rasgos fundamentales de las estrategias que movilizan los actores.

Primero, la condición de vulnerabilidad de la tenencia estructura la vida cotidiana, los vínculos sociales de los residentes, y organiza las estrategias que adoptan los actores. Los residentes conocen los problemas asociados a la precarización de la propiedad y tenencia, y han recibido asesorías e información acerca de su situación legal. Frente a esto, sus estrategias van desde la decisión de pagar impuestos o alquileres en determinados periodos de tiempo para mantener un estatus de tenencia. Es decir, incorporan los marcos legales como parte de sus estrategias, lo cual se expresa en materialidades (documentos, planos, recibos de pago, entre otros) que permiten justificar su derecho a la vivienda y legitimar su posibilidad de mantener su lugar de residencia.

Y utilizan estos mismos marcos normativos para reconocer la importancia de que los propietarios no "cuiden" sus inmuebles. Luego de 10 años de ausencia de los propietarios, el residente puede solicitar la prescripción administrativa y solicitar la propiedad de su vivienda. Así, los residentes esperan que el paso del tiempo les permita iniciar el proceso de solicitud de la propiedad, pero manteniendo una serie de estrategias para establecer el vínculo con la propiedad. Un caso típico sería el residente que realiza el pago del impuesto predial como forma de poder probar posteriormente derechos sobre la vivienda. O realiza el pago del alquiler cada cierto tiempo para no caer en situación de posesión precaria. Si llegara a encontrar en condición de posesión precaria, entonces también reconocen las acciones y límites legales que deben adoptar sus estrategias.

En muchos casos, estos documentos no aseguran una defensa a los desalojos. Es el caso de María y sus vecinos, quienes fueron desalojados de manera arbitraria. No tenían título de propiedad de la vivienda que habitaban, pero sí tenían derechos 
sobre el predio, puesto que pagaban impuestos del inmueble desde hace varias décadas. Las estrategias que permiten sumar documentos a los residentes (como el pago de impuestos), solo atenúan la inseguridad de la tenencia en el ámbito legal, pero no establecen un insumo para la defensa en estos casos, donde lo legal e ilegal están imbricados. El marco legal otorga incentivos para todos los actores involucrados. El tema de los propietarios es el problema central de estos predios. Debido a que el proceso de subdivisión y alquiler de estos predios adquiere mayor importancia a inicios del siglo $\mathrm{XX}$-en tanto estrategia rentista-, con el paso del tiempo, el fallecimiento de los propietarios originales, juicios entre los herederos y falta de interés, etc.; se genera una situación de procesos irregulares de compra y venta (en algunos casos ficticios e ilegales) que son una constante. Vale advertir que existe otro tipo de propietarios -como son la Municipalidad y otras instituciones- que operan bajo distintos esquemas normativos. En el caso de propietarios (reales o ficticios), utilizan estrategias como el cobrar montos de alquiler mínimos o establecer una presencia cada cierto tiempo en el predio, con el fin de reducir las posibilidades de perder un juicio por abandono del predio.

Segundo, la precarización de la propiedad se manifiesta en la falta de claridad en quiénes son los propietarios y las características del régimen precario de inquilinato. En Barrios Altos existen juicios debido a falta de propietarios, juicios entre los herederos de los propietarios originales, o juicios por acciones de compra y venta no regulares. Estos propietarios "reales o ficticios" esperan que el mercado del suelo se modifique. Existen dos características centrales del mercado de suelo de esta área: por un lado, los problemas de falta de infraestructura de servicios básicos (agua, saneamiento) en un número importante de predios. Barrios Altos es una zona poco atractiva para la inversión privada en vivienda u oficinas, debido a los problemas de infraestructura y a la estigmatización como zona insegura. En este contexto, el uso comercial (depósitos o galerías) de los predios aparece como la mejor (o única) forma de obtener ganancias de estos predios.

Esta situación otorga un espacio de acción para los residentes, una oportunidad en términos legales. El caso de una quinta -explicada por un miembro de una asociación de vivienda- puede ayudar a entender la magnitud de esta situación:

"Esta quinta tiene 100 años de antigüedad, fue comprada por una familia italiana y de ahí pasó a otro dueño y después pasó a otro dueño, al morir toma el poder sus hijos ¿ya? Y de los dos hijos, cuando muere uno, le tocó esta quinta a una hija mujer, pero esta hija mujer en el año 60 fallece, pero no tenía herederos. Esta quinta ha tenido mucho vacío legal. A inicios de los ochenta, aparece un sobrino como heredero y se lo vendió a un comerciante del mercado central". 
Tercero, los incentivos para la acción colectiva. Las viviendas colectivas involucran una constante negociación de las pautas de convivencia. Los espacios comunes, la limpieza o, en algunos casos, los servicios compartidos se convierten en los temas centrales para los que los residentes deben actuar colectivamente. A esta situación se suma que las normas de renovación urbana en distintos momentos han establecido como uno de los requisitos fundamentales la existencia de una asociación de residentes en cada inmueble. En el caso de los residentes del CHL, la participación y organización de los posesionarios de predios ha seguido una lógica defensiva, con la aprobación de la Ley de Saneamiento Físico y Legal de Predios Tugurizados (Ley 29415) y su respectivo Reglamento. Esta situación la explica con claridad un residente:

"Antes de conocer la ley nosotros nos organizábamos por temas específicos, por ejemplo arreglar la quinta, limpiarla, tratar de buscar la forma de que los recibos de agua no se vencieran. Pero una vez que conocimos la ley vimos que había una posibilidad de hacer mejoras sustanciales en el predio ¿no? [...] La ley nos abrió los ojos, la ley nos dijo bueno al final de cuentas ustedes como posesionarios pueden lograr muchas cosas porque la ley como posesionarios porque la ley nos dice que podemos... son tres alternativas: el mejoramiento de los predios, el apuntalamiento...el hacer los cambios de agua, desagüe y el otro sería derrumbar todo y hacer un predio nuevo."
Cuarto, el desalojo en el contexto de las últimas dos décadas opera en un doble sentido. Por un lado, es una disrupción de los procesos de espera en la que se encuentran propietarios y residentes. Espera en la cual van implementando estrategias en el marco de lo legal/ilegal, que permitan luego sustentar legalmente derechos a la propiedad. Disrupción que reestructura la vida cotidiana y estrategias residenciales de los habitantes. Pero al mismo tiempo, el desalojo es una situación previsible para los residentes.

Los desalojos existen como posibilidad y estructuran el tiempo social de los residentes (Harms, 2013). Pero hay que diferenciar aquellos casos en que las personas forman parte de un proceso "relativamente delimitado" de desalojo debido a la implementación de un proyecto urbano a situaciones, en que el desalojo forma parte de un repertorio posible (pero no seguro) o donde priman criterios de incertidumbre. Los marcos de referencia para responder a las preguntas de "cuándo" y "cuánto tiempo" son diferentes dependiendo de los casos. El tiempo es un instrumento de poder (Harms, 2013) y la espera constituye una manifestación de relaciones de dominación (Auyero, 2012). La posibilidad de desalojo -como manifestación de la precariedad urbana- involucra una espera que normaliza la incertidumbre en la que viven los residentes. Los propietarios también esperan, como especulación urbana. La especulación urbana se sustenta en la espera como forma de mantener un 
FIGURA 4. BARRIOS ALTOS.

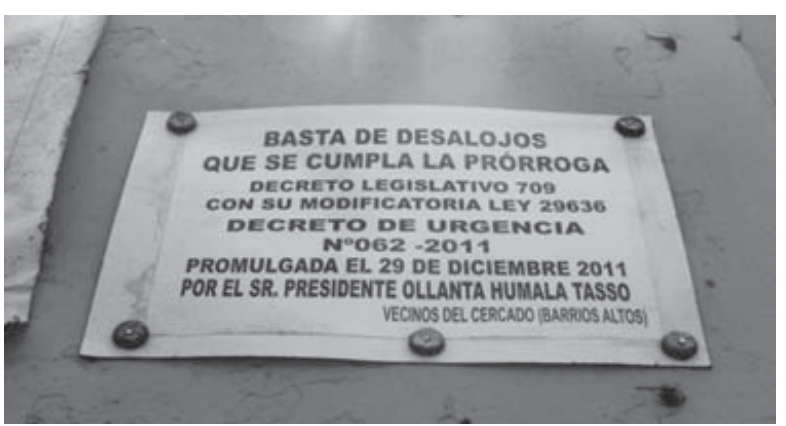

Fotografía de Tania Ramírez (2013).

capital (que no implica que sea un capital inmóvil) con la expectativa de obtener mayores ingresos por el uso o venta del predio. La coyuntura de las últimas décadas ha otorgado incentivos a propietarios e interesados en los inmuebles de Barrios Altos.

Cuarto, la ejecución de los desalojos involucra contextos de negociación y de imposición a través de la violencia, uso de mecanismos ilegales y el desarrollo de un entramado ilegal de tráfico de terrenos. Los residentes poseen un conocimiento abundante sobre la titularidad de los predios, respaldado por documentos y por el relato de familias que residen en el mismo espacio desde hace muchas décadas. Esto les permite establecer elementos de seguridad relativa acerca la tenencia. En otros casos, los mismos residentes reconocen la ausencia de dueños, que se traduce en la falta de regularización de los títulos de propiedad y en la inexistencia de un documento legal definitivo que identifique al propietario. Esta situación de precarización de la propiedad genera las condiciones para un mercado ilegal de la propiedad, que se expresa en distintos traspasos de la propiedad hasta que alguna persona logre inscribir el título y regularizar la situación. El ámbito de lo legal articula en torno a distintas prácticas ilegales, que pueden ir desde títulos falsos hasta la corrupción en el aparato burocrático estatal para ser beneficiados.

Las actividades irregulares en los procesos de desalojo aparecen como tema recurrente en las conversaciones de los residentes. Luis es el ex presidente de una asociación de vivienda de un inmueble que se encuentra inmerso en una serie de procesos judiciales de propiedad. Uno de los procesos judiciales se relaciona con la venta del inmueble que efectuó un grupo de comerciantes. Los compradores realizaron la compra asumiendo que todos los residentes del inmueble eran precarios, es decir, no tenían contrato de alquiler. Por esta razón plantearon una demanda de desalojo a toda la asociación como conjunto, sin embargo, varios de los residentes sí tenían un documento que respaldaba su situación como inquilinos, y debido a esto desestimaron la demanda en la segunda instancia del proceso judicial. Los desalojos son un repertorio utilizado de manera legal e ilegal en condiciones en que no se logra un acuerdo entre residentes y las personas interesadas en el predio. 
FIGURA 5. BARRIOS ALTOS.

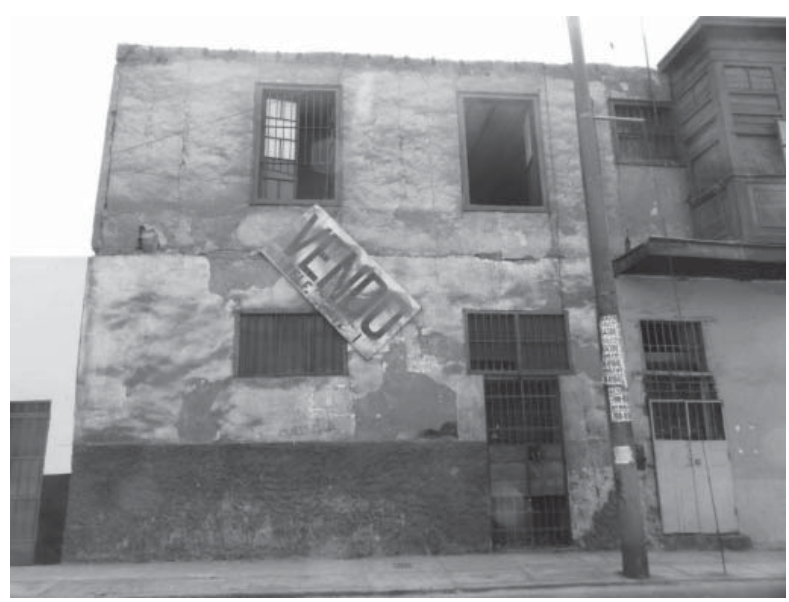

Fotografía de Tania Ramírez (2013).

Los desalojos no son solo resoluciones judiciales o legales. Por el contrario, el desalojo opera de distintas maneras. En muchos casos, lo importante es la demanda de desalojo, la cual no solo legitima las acciones (violentas o no) que se realizan con el fin de poder acceder al control del predio, sino que sirve de marco de negociación con los residentes. Así, es posible señalar un gradiente de casos de desalojo. En un extremo, están los procesos de negociación, donde los propietarios realizan un pago a los residentes para que abandonen el predio.

Otra posible situación -con rasgos similares- es que los propietarios logran convencer a un grupo de residentes de abandonar el predio. En este escenario, y con un predio con abandono parcial, se identifican dos estrategias: el propietario ejecuta un proceso de desalojo legal o inicia una serie de acciones que violenten contra la seguridad de los residentes o del predio. En el otro extremo, los desalojos involucran procesos de imposición y violencia. Algunas de las estrategias utilizadas para tomar posesión de los predios son los incendios, usar el agua para debilitar las estructuras físicas de los inmuebles o la acción violenta de personas. Lo que interesa no es apropiarse del terreno para fines residenciales, por lo que el cuidado de la materialidad del inmueble es algo de menor importante para los futuros propietarios.

\section{Conclusiones}

Este artículo responde al llamado de autores como Arabindoo (2011) de estudiar la reproducción de los espacios de pobreza urbana desde su historicidad y las prácticas de los actores. Esto permite superar el uso descriptivo de categorías como tugurios, para comprender su configuración en torno a procesos generales y estrategias a nivel micro. Además, discute un caso poco atendido atendido por los estudios urbanos en las últimas décadas: los procesos de transformación en áreas centrales "deterioradas". Delgadillo (2016b) propone tomar con cuidado el traslado automático de categorías 
para estudiar casos en nuestra región. La categoría de gentrificación se ha convertido en central en el debate sobre las transformaciones de áreas centrales en América Latina ${ }^{8}$. Esta literatura es indispensable para comprender los mecanismos de acumulación de capital y procesos de transformación urbana. Sin embargo, tiene limitaciones para comprender procesos como el descrito en este artículo. Como señala Ghertner (2015), el problema de la importancia que ha obtenido el debate sobre gentrificación es que en casos como Barrios Altos -donde la propiedad no está regularizada- se invisibilizan otro tipo de procesos de desplazamiento y conflictos que configuran el CHL.

La discusión planteada a lo largo del texto permite señalar cuatro argumentos de cierre. Primero, es necesario recuperar una de las particularidades en la configuración de las áreas centrales históricas de América Latina y Lima: la tensión estructurante del centro histórico es la coexistencia de funciones urbanas de centralidad y residenciales. Los conflictos por el uso del suelo se dan en un contexto de desarrollo restringido del mercado de suelo (baja rentabilidad para proyectos residenciales o de otro tipo). Adicional, la debilidad de las políticas públicas de renovación urbana, pese al avance en instrumentos normativos y legales, no han logrado mejorar las condiciones de vida de los residentes y/o disminuir los conflictos por los predios y la forma en que se resuelven.

Segundo, el desplazamiento, desposesión y desalojo ocurren en los márgenes de lo legal, irregular e ilegal. Los conflictos por el uso del suelo no están asociados a grandes proyectos públicos o privados, ni involucra actores inmobiliarios formales. Estamos frente a actores que actúan dentro de lo formal/informal (legal/ilegal) como un continuo en el que las acciones estatales presentan incentivos para ambos actores en conflicto. Distintos actores movilizan estrategias que juegan en el marco de lo legal, pero bajo prácticas en los márgenes de lo legal e ilegal. Los conflictos por el uso del suelo se dan debido a la presión de actores económicos vinculados a los espacios comerciales del CHL para contar con espacios de mayor proximidad para uso de galerías y depósitos; y, en segundo plano, a las dinámicas de especulación del valor del suelo.

Tercero, el desalojo opera como un evento organizador de las estrategias utilizadas por los distintos actores involucrados. La mitad de los residentes viven en situación de alquiler y se encuentra en riesgo de ser desalojados. Pese a la existencia de distintos arreglos de la propiedad y tenencia, este tipo de áreas permite comprender una de las razones por la que los centros históricos de varias

8 Uno de los mejores balances sobre esta discusión se puede consultar en: Janoschka, Sequera y Salinas (2014). 
ciudades en la región han perdido población. La precariedad urbana es un rasgo estructural y tiene repercusiones en la administración de la vida cotidiana, el uso de los recursos y las negociaciones entre actores (Muñoz, 2017).

Cuarto, existen formas visibles e invisibles de regular la pobreza urbana (Auyero, 2010). Un ejemplo adicional sería la precariedad que experimentan los residentes de áreas como Barrios Altos como resultado de la ausencia de una política de renovación urbana. Los residentes reconocen la posibilidad de ser desalojados, que sin duda genera efectos perversos en su calidad de vida y la acumulación de desventajas sociales. La posibilidad de desalojo estructura la vida de los residentes y la espera articula la estrategia tanto de los residentes como de los interesados en adquirir la propiedad de los predios para otros usos. Esto implica reconocer las desventajas estructurales que poseen los residentes, pero también asumir la importancia de reconocerlos como sujetos activos. Es decir, como agentes que tratan de resolver o enfrentar de distintas maneras la inseguridad de la tenencia de sus viviendas y asegurar la reproducción de sus condiciones de vida.

A sus casi 50 años, Juan reside en Barrios Altos desde hace más de dos décadas. Su inserción residencial se dio gracias a la compra de un "traspaso" en unas de las quintas que existen en esta zona, de la cual tuvo información gracias a un contacto familiar. Luego de algunos años de haber residido en este espacio, fue desalojado él y su familia. Ahora ha logrado acceder a otro espacio -que no supera los 25 metros cuadrados- en una quinta ubicada a unas cuadras de la anterior, y que servirá de espacio residencial para toda la familia. Unos meses antes de la entrevista, se le avisó que un "nuevo" propietario había aparecido reclamando la propiedad del predio y había iniciado juicios individuales a todos los inquilinos y posesionarios (precarios o no) para desalojarlos. Dice que hay una asociación vecinal en la cual participa y que es importante mantenerse informado. Sin embargo, lo más posible es que vuelva a enfrentar un proceso de desalojo y quizás lo mejor sea conciliar y recibir un pago de parte de este nuevo propietario para abandonar el espacio, y utilizar este pago para buscar otro en el mismo barrio.

De manera paralela a las transformaciones del CHL que se concentran en las plazas principales, en la apertura de negocios para sectores medios o la recuperación de ciertos inmuebles monumentales; existe otro proceso que pasa desapercibido, y que silenciosamente continúa deteriorando las condiciones de vida de los residentes. Estas tendencias no son contradictorias, sino que consolidan un modelo de fragmentación urbana en las áreas centrales (Borsdorf e Hidalgo, 2013).

Este artículo se ha centrado en este segundo proceso, en destacar cómo la precariedad urbana se expresa en la inseguridad de la tenencia y los 
FIGURA 6. BARRIOS ALTOS.

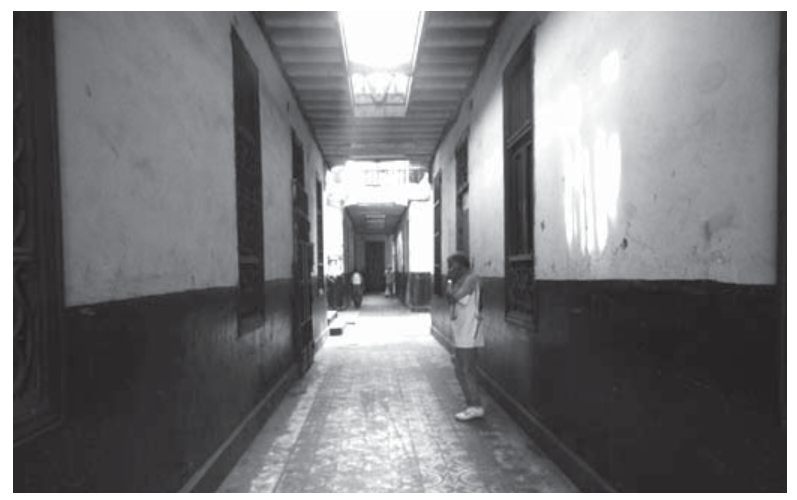

Fotografía de Tania Ramírez (2013).

conflictos por el suelo, es decir, en los casos como el de Juan. Los residentes normalizan la incertidumbre a través de estrategias que operan en los márgenes de lo legal e ilegal. La incertidumbre no desaparece, solo logra ser controlada. Los residentes esperan a que los cambios no lleguen a ellos, aunque poco a poco el carácter residencial de Barrios Altos desaparezca.

\section{Referencias bibliográficas}

Abramo, P. (2012). La ciudad com-fusa: mercado y producción de la estructura urbana en las grandes metrópolis latinoamericanas. EURE, 38(114), 35-69. https://doi.org/10.4067/ S0250-71612012000200002.
Arabindoo, P. (2011). Rhetoric of the "slum": Rethinking urban poverty. City, 15(6), 636-646. https://doi.org/ 10.1080/13604813.2011.609002.

Arroyo, E. (1994). El centro de Lima, uso social del espacio. Lima: Fundación Friedrich Ebert.

Auyero, J. (2010). Visible fists, clandestine kicks, and invisible elbows: three forms of regulating neoliberal poverty. European Review of Latin American and Caribbean Studies, (89), 5-26. https://doi. org/10.18352/erlacs.9455.

Auyero, J. (2012). Patients of the state: The politics of waiting in Argentina. Durham, NC: Duke University Press.

Borsdorf, A. e Hidalgo, R. (2013). Revitalization and tugurization in the historical centre of Santiago de Chile. Cities, 31, 96-104. https://doi.org/10.1016/j. cities.2012.09.005.

Brickell, K., Fernández Arrigoitia, M., y Vasudevan, A. (Eds.). (2017). Geographies of forced eviction. dispossession, violence, resistence. Londres: Palgrave.

Calderón, J. (2005). La ciudad ilegal: Lima en el siglo XX. Lima: Fondo Editorial de la Facultad de Ciencias Sociales UNMSM.

Calderón, J. (2014). El potencial del alquiler en la política de vivienda de Perú. Blanco. En: A.G. Blanco, V. Fretes Cibils, y A.F. Muñoz (Eds.). Busco casa en arriendo. Promover el alquiler tiene sentido. Washington D. C.: BID.

Carrión, F. (1992). Lógica del tugurio. Panorama, (3), 52-59. 
Carrión, F. (2010). El laberinto de las centralidades históricas en América Latina. El centro histórico como objeto de deseo. Quito: Ministerio de Cultura de Ecuador.

Chion, M. y Ludeña, W. (2005). Chion, M. y Ludeña, W. (2005). Espacios públicos, centralidad y democracia. El centro histórico de Lima. Periodo 19802004. Ur[b]es, 2(2), 145-169.

Chirinos, L. (1996). Barrios céntricos de inquilinato en Lima. Los barrios Monserrate, Barrios Altos y Mendoza Merino. En H. Harms, W. Ludeña y P. Pfeiffer (Eds.). Vivir en el "centro". Vivienda e inquilinato en los barrios céntricos de las metrópolis de América Latina. Hamburgo: Universidad de Hamburgo.

Coulomb, R. (2012). El centro de la Ciudad de México frente al desafío de un desarrollo urbano más sustentable. En: R. Coulomb, M.T. Esquivel y G. Ponce (Coord.). Hábitat y centralidad en México: un desafío sustentable. México D.F.: Centro de Estudios Sociales y de Opinión Pública.

Custers, G. (2001). Inner-city rental housing in Lima: A portrayal and an explanation. Cities, 18(4), 249-258. https://doi.org/10.1016/ S0264-2751(01)00017-8.

Dammert Guardia, M. (2017). Vivienda, centralidad y conflicto. En P. Ramírez Kuri (Coord.). La erosión del espacio público en la ciudad neoliberal. Ciudad de México: Universidad Autónoma de México.

Delgadillo, V. (2008a). Mejoramiento habitacional en las áreas urbanas centrales de América Latina. Del combate de tugurios a la rehabilitación habitacional progresiva. Revista INVI, 23(63), 89-119. Recuperado de http://revistainvi.uchile. cl/index.php/INVI/article/view/444.

Delgadillo, V. (2008b). Repoblamiento y recuperación del centro histórico de la ciudad de México, una acción pública híbrida, 2001-2006. Economía, Sociedad y Territorio, 8(28), 817-845. https://doi. org/10.22136/est002008219

Delgadillo, V. (2016a). Selective modernization of Mexico City and its historic center. Gentrification without displacement? Urban Geography, 37(8), 1-21. https://doi.org/10.1080/02723638.2015.10 96114

Delgadillo, V. (2016b). Patrimonio urbano en la Ciudad de México. La herencia disputada. Ciudad de México: UACM.

Desmond, M. (2012). Eviction and the reproduction of urban poverty. American Journal of Sociology, 118(1), 88-133. https://doi.org/10.1086/666082

Desmond, M. (2016). Evicted. Poverty and profit in the American City. Nueva York: Crown Publishers.

Desmond, M. y Bell, M. (2015). Housing, poverty, and the law. Annual Review of Law and Social Science, 11, 15-35. https://doi.org/10.1146/ annurev-lawsocsci-120814-121623

Desmond, M. y Shollenberger, T. (2015). Forced displacement from rental housing: Prevalence and neighborhood consequences. Demography, 52(5), 1751-1772. https://doi.org/10.1007/ s13524-015-0419-9 
Dreifuss Serrano, C. (2005). Ciudad y vivienda colectiva republicana en el Perú. El "callejón" de Petateros. Transformaciones. Ur[b]es, 2(2).

Driant, J. (1991). Las barriadas de Lima. Lima: IFEA-DESCO.

Duhau, E. \& Giglia, A. (2004). Las reglas del desorden. Habitar la metrópoli. México D.F.: Siglo XXI.

Escenario de riesgo sísmico y medidas de mitigación en el centro histórico de Lima-Rímac. (2011). Lima: INDECI.

Ghertner, D.A. (2015). Why gentrification theory fails in "much of the world". City, 19(4), 552-563. https:// doi.org/10.1080/13604813.2015.1051745

Gonzales, E. y Pozo, J.M.d. (2012). Lima, una ciudad policéntrica. Un análisis a partir de la localización del empleo. Revista Investigaciones Regionales, (23), 29-52.

Hardoy, J.E. y Gutman, M. (1995). Impacto de la urbanización en centros históricos de Iberoamérica: tendencias y perspectivas. Madrid: Mafre.

Harms, E. (2013). Eviction time in the new Saigon: Temporalities of displacement in the rubble of development. Cultural Anthropology, 28(2), 344-368. https://doi.org/10.1111/cuan.12007

Harms, H. (1997). To live in the city centre: Housing and tenants in central neighbourhoods of Latin American cities. Environment and Urbanization, 9(2), 191-212. https://doi. org/10.1177/095624789700900209
Hartman, C. y Robinson, D. (2003). Evictions: The hidden housing problem. Housing Policy Debate, 14(4), 461-501. https://doi.org/10.1080/10511482 .2003 .9521483

Henry, E. (1977). Los asentamientos urbanos populares: un esquema interpretativo. Debates en Sociología, (1), 109-138. Recuperado de http://revistas.pucp. edu.pe/index.php/debatesensociologia/article/ view/6774.

Hiernaux, D. y González, C.I. (2008). ¿Regulación o desregulación?: de las políticas sobre los centros históricos. Centro-h, (1), 40-50.

Janoschka, M. (2016). Gentrificación, desplazamiento, desposesión: procesos urbanos claves en América Latina. Revista INVI, 31(88), 27-71. https://doi. org/10.4067/S0718-83582016000300002

Janoschka, M., Sequera, J., y Salinas, L. (2014). Gentrification in Spain and Latin America - a critical dialogue. International Journal of Urban and Regional Research, 38(4), 1234-1265. https://doi. org/10.1111/1468-2427.12030

Ludeña, W. (2002). Lima: poder, centro y centralidad: Del centro nativo al centro neoliberal. EURE, 28(83), 45-65, https://doi.org/10.4067/ S0250-71612002008300004

Ludeña, W. (2011). Lima. Reestructuración económica y trasformaciones urbanas: periodo 1990-2005. Cuadernos Arquitectura y Ciudad, (13).

Muñoz, S. (2018). Precarious city: Home-making and eviction in Buenos Aires, Argentina. 
Cultural Geographies, 25(3), 411-424. https://doi. org/10.1177\%2F1474474017719068

Panfichi, A. (1995). Urbanización temprana de Lima, 1535-1900. En: A. Panfichi y F. Portocarrero (Eds.), Mundos interiores: Lima 1850-1950. Lima: Universidad del Pacífico.

Panfichi, A. (2013). Sociología de los barrios populares del centro de Lima, siglo XX. En: C. Aguirre y A. Panfichi (Eds.), Lima, siglo XX. Cultura, socialización y cambio. Lima: PUCP.

Pírez, P. (2016). Las heterogeneidades en la producción de la urbanización y los servicios urbanos en América Latina. Territorios, (34), 87-112. https:// doi.org/10.12804/territ34.2016.04

Programa de Naciones Unidas para el Desarrollo. (2005). Diagnóstico de la precarización de la propiedad urbana. Lima: autor

Purser, G. (2016). The circle of dispossession: Evicting the urban poor in Baltimore. Critical Sociology, 42(3), 393-415. https://doi. org/10.1177/0896920514524606

Rao, U. (2013). Tolerated encroachment: Resettlement policies and the negotiation of the licit/illicit divide in an Indian metropolis. Cultural Anthropology, 28(4), 760-779. https://doi.org/10.1111/ cuan. 12036

Rojas, E., Rodríguez, E., y Wegelin, E. (2004). Volver al centro. La recuperación de áreas urbanas centrales. Nueva York: Banco Interamericano de Desarrollo.
Rodríguez, M.C., Rodríguez, M.F., y Zapata, M.C. (2018). Mercantilización y expansión de la inquilinización informal en Villas de Buenos Aires, Argentina. Revista INVI, 34(93), 125-150. https://doi. org/10.4067/S0718-83582018000200125

Sánchez León, A., Guerrero, R., y Calderón, J. (1979). Tugurización en Lima metropolitana. Lima: DESCO.

Slater, T. (2006). The eviction of critical perspectives from gentrification research. International Journal of Urban and Regional Research, 30(4), 737-757. https:// doi.org/10.1111/j.1468-2427.2006.00689.x

Toscani, M. (2018). Dinámica de los hoteles pensión y los desalojos del barrio de Constitución. Aproximaciones desde la dimensión de poder. Quid 16, (9), 139-152. Recuperado de https://publicaciones.sociales.uba.ar/index.php/quid16/article/ view/2892 